\title{
ATRESIA DE VÍAS BILIARES EXTRAHEPATICAS EN PEDIATRIA Y CITOMEGALOVIRUS COMO CAUSANTE
}

\section{EXTRAHEPATIC BILIARY ATRESIA IN PEDIATRICS AND CYTOMEGAlOVIRUS AS A CAUSE}

Isabel Antonieta Rejas Villegas

\section{RESUMEN}

'Médico General, postgraduante en educación superior basada en evidencias, Unidad de post-grado de la Facultad de Ciencias de la Salud UAGRM.

Correspondencia a: Santiago Villalobos Guarin Correo electrónico: isabelrv1994@gmail.com Telefono: 70202563

\begin{abstract}
Palabras clave: Atresia biliar, citomegalovirus, portoenterostomia hepática.
\end{abstract}

Keywords: Biliary atresia, cytomegalovirus, hepatic portoenterostomy.

Procedencia y arbitraje: no comisionado, sometido a arbitraje externo.

Recibido para publicación: 21 de septiembre 2019 Aceptado para publicación: 7 de julio de 2020

Citar como:

Rejas Villegas IA. Atresia de vias biliares extrahepaticas en pediatria y citomegalovirus como causante: reporte de un caso en Santa Cruz Bolivia. Rev Cient Cienc Med. 2020; 23(1): 92-96

\section{INTRODUCCIÓN}

Sa trata de una malformación que afecta intrahepaticas, lo cual produce una obstrucción en la salida de la bilis dentro de los 3 primeros meses de vida, origen desconocido, predominio en sexo femenino, la morbimortalidad a nivel global es de 1 cada 9000 a 12,000 nacidos vivos. ${ }^{1,2,3}$ Existen 2 variantes: fetal y perinatal, en esta última el árbol biliar se destruye después del parto por un proceso inflamatorio que se asocia a una infección de origen viral adquirida transplacentariamente. ${ }^{1}$ La producción de CD13 autoanticuerpos específicos, pueden promover la inflamación y el daño tisular en los casos de atresia de vias biliares y se ha sugerido que la infección por el virus del Citomegalovirus es una causa. ${ }^{4}$ Histológicamente la colestasis y la proliferación de conductillos biliares periportales en el hígado son evidentes, a veces se observa hepatocitos gigantes multinucleados. ${ }^{5}$ Al presentar ictericia, acolia y hepatomegalia, el abordaje inicial es confirmar la colestasis para descartar otros cuadros que cursan con hiperbilirrubinemia indirecta. ${ }^{6}$ Se valora el análisis de Toxoplasmosis, Rubeola, Citomegalovirus, Herpes y Hepatitis vírica en el paciente como en la mujer embarazada, a esta última para anteponerse al desarrollo de la patología.7, 8 Se refuerza con una ecografía, gammagrafía, biopsia hepática que es útil para la evaluación del grado de fibrosis y por ultimo con una colangiografia. ${ }^{9,10}$ El tratamiento de 
elección es la portoenterostomia de kasai. ${ }^{10}$

El objetivo de este artículo es reportar un caso clínico de un paciente pediátrico con atresia de vias biliares, enfatizar en el valor de la semiología para lograr un diagnóstico y tratamiento precoz, lo que permite intervenciones quirúrgicas oportunas.

\section{PRESENTACIÓN DEL CASO}

Paciente femenino de 4 meses de edad, natural y procedente de Robore (Santa cruz Bolivia), producto de la segunda gestación, pretérmino, con ictericia al nacimiento, esquema de vacunación completo para la edad; con un cuadro aproximadamente 7 días de evolución, presentando hematemesis, caracterizado por sangre oscura, más o menos 4-5 veces en escasa cantidad, acompañado de acolia, mas adelante presentó melenas, fiebre no cuantificada, adinamia, astenia, anorexia, por lo que es llevado al hospital de Robore donde es tratada con antipirético IM, y posteriormente referido al Hospital "Japonés" para valoración y conducta.

En la valoración se aprecia ictérica con una puntuación de 5 en la escala de Kramer, edema generalizado, macroglosia, abdomen globoso, hernia umbilical reductible, hígado palpable a 4 centímetros debajo del reborde costal derecho, bazo palpable a 6 centímetros debajo del reborde costal izquierdo, equimosis en sitios de venopunción en extremidades inferiores, resto del examen físico sin evidencia de alteraciones.

Con una impresión diagnostica de hepatitis aguda, atresia de vias biliares, sepsis, intoxicación por paracetamol, falla hepatica aguda, se toma la conducta de: Nada por vía oral (NPO), colocación de sonda nasogástrica, hidratación endovenosa a $100 \mathrm{ml} / \mathrm{kg}$ con cloruro de sodio a $3 \mathrm{meq} / \mathrm{kg} /$ dia, cefotaxima 70mg endovenoso (EV) cada 6 horas, amikacina $60 \mathrm{mg}$ EV cada 12 horas, Dipirona $100 \mathrm{mg}$ EV en caso de que presente fiebre, ranitidina $20 \mathrm{mg}$ EV cada dia, vitamina K 10mg EV cada día, crioprecipitados, plasma fresco congelado, exámenes y laboratorios complementarios, interconsulta con cirugía pediátrica y gastroenterología.

Se realizaron estudios laboratoriales que reportaron anemia con hemoglobina 5,9 gr/dl, prolongación de tiempo de protrombina 17.5 segundos, hematocrito $16.9 \%$, hepatopatía con AST 227U/L, ALT $243 \mathrm{U} / \mathrm{L}$, colestasis con bilirrubina total 23,6 mg/dl, bilirrubina directa 19,6 mg/dl, bilirrubina indirecta 4 mg/dl (Tab. 1). Se inicia tratamiento con transfusión de crioprecipitados, concentrado de eritrocitos y plasma fresco congelado, con posterior control de tiempo de protrombina. Al estudio de laboratorio pos transfusión se reportó prolongación de tiempo de protrombina

Tabla 1: Estudios laboratoriales al ingreso a emergencia, con fecha del 07 de Noviembre del 2018.

\begin{tabular}{|c|c|c|c|c|c|c|c|c|}
\hline GB & HGB & PLAQ & HTO & TP & TC & TS & GOT & GTP \\
\hline $\begin{array}{l}15,600 \\
\mathrm{~mm} 3\end{array}$ & dl $5.9 \mathrm{gr} /$ & $\begin{array}{l}167,000 \\
\mathrm{~mm} 3\end{array}$ & $16.9 \%$ & $\begin{array}{l}17.5 \\
\text { seg }\end{array}$ & $8 \mathrm{~min}$. & $2 \min$ & $\begin{array}{l}227 \\
U / L\end{array}$ & $\begin{array}{l}243 \\
U / L\end{array}$ \\
\hline BT & BD & $\mathrm{BI}$ & HIV & & & & & \\
\hline $\begin{array}{r}23.6 \\
\mathrm{mg} / \mathrm{dl}\end{array}$ & $\begin{array}{r}19.6 \\
\mathrm{mg} / \mathrm{dl}\end{array}$ & dl $4.0 \mathrm{mg} /$ & $(-)$ & & & & & \\
\hline
\end{tabular}

GR/DL = gramos/decilitro, U/L = unidades/litro, MG/DL = miligramos decilitro, MM3 = milímetro cubico, SEG = segundos, MIN = minutos

Tabla 2: Estudio laboratorial post transfusión, con fecha del 07de Noviembre del 2018.

TAB. 2: Estudio de laboratorio pos transfusión
$\begin{array}{ll}(07 / 11 / 2018) & \\ \text { TP } & \text { ACTIVIDAD } \\ 17.5 \mathrm{seg} & 42 \%\end{array}$


17.5 segundos y actividad de $42 \%$ (Tab. 2). En el segundo día de internación el servicio de gastroenterología indica como presunto diagnóstico de colestasis, hipotiroidismo probable, por lo que solicita ecografía abdominal, endoscopia digestiva alta, transfusión de plasma fresco congelado diariamente, laboratorios de perfil tiroideo y exámenes complementarios. Ese mismo dia el servicio de cirugía pediátrica propone como diagnóstico probable hipotiroidismo secundario basado en la valoración del examen físico, atresia de vias biliares y hernia umbilical, tomando como tratamiento: descartar patología de manejo clínico, al momento sin indicación quirúrgica, ecografía abdominal, herniorrafia umbilical cuando paciente se encuentre en condiciones óptimas.

Al 3er. dia de internación al no haber mejoría expectante se reevalúa y es ingresada al servicio de Unidad de Terapia Pediátrica, ese mismo día se realizó la ecografía abdominal el cual reporto: Hígado hiperecogenico, rodeado delíquido ascítico, bordes netos, ecogenecidad homogénea, vasos intrahepaticos con mala visualización (Fig. 1), bordes engrosados de la vesícula biliar, contenido econegativo, no se detecta vías biliares, en especial no se detecta colédoco, ni se observa el signo del cordón. (Fig. 2)

Conclusión: compatible con atresia de vías biliares. Se realizan exámenes laboratoriales de control y serología viral para citomegalovirus, toxoplasmosis, hepatitis A, B, Cy VIH, los cuales reportan anemia con hemoglobina 5,9 gr/dl, plaquetopenia con 17,300 mm3, hepatopatía con AST $80 \mathrm{U} / \mathrm{L}, \mathrm{ALT} 140 \mathrm{U} / \mathrm{L}$, colestasis con bilirrubina total $14.8 \mathrm{mg} / \mathrm{dl}$, bilirrubina indirecta $2.9 \mathrm{mg} / \mathrm{dl}$, bilirrubina directa 11.9 mg/dl y positivo para citomegalovirus (Tab. 3 y 4). Se indica transfusión de concentrado de eritrocitos y se continúa con plasma fresco congelado. El servicio de gastroenterologia descontinua la solicitud de endoscopia digestiva alta y análisis debido a alteración de coagulación y al resultado serológico de citomegalovirus positivo. Al 4to dia se solicita una re interconsulta con cirugía pediatría para nueva valoración con resultados de ecografía y laboratoriales, quienes llegan al diagnóstico de Atresia de vias biliares extrahepaticas, indicando como conducta: tratamiento quirúrgico, sin embargo por la

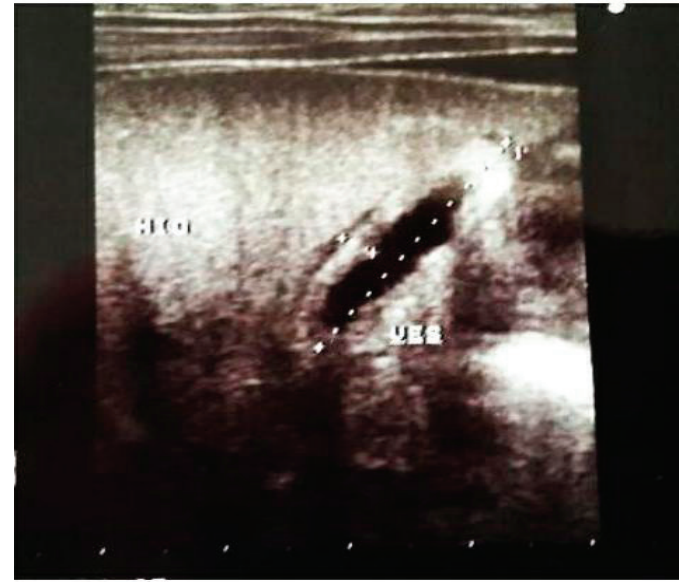

Figura 1: Ecografia abdominal, se evidencia hígado hiperecogenico, con mala visualización de vasos intrahepaticos y presencia de líquido ascítico rodeando el hígado y la vesícula.

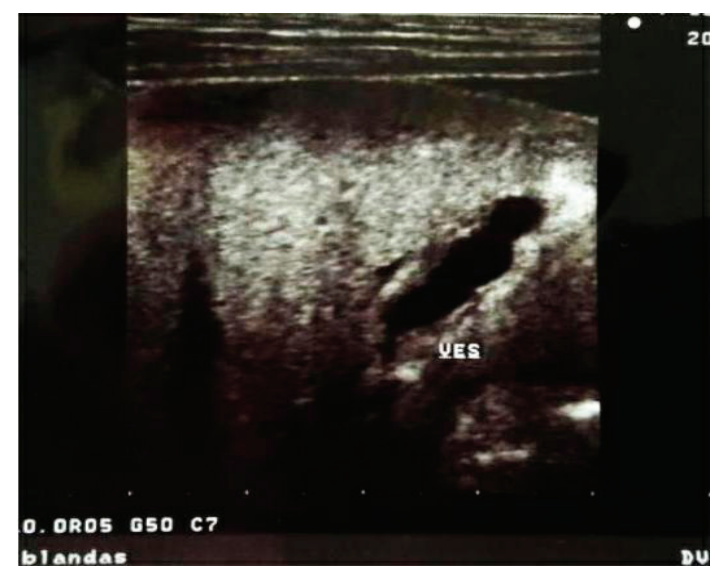

Figura 2: Ecografia abdominal, se evidencia vesícula con contenido econegativo, engrosamiento de la pared vesicular, no se detectan vías biliares, ni colédoco.

edad de la paciente es dificultoso proseguir con la indicación, por lo que cirugía pediátrica indica proseguir con tratamiento paliativo, al no poderse realizar portoenterostomia de kasai y la dificultad para realizar un trasplante hepático. Queda en terapia intensiva pediatría por 4 días y posteriormente es trasladada a sala pediátrica, quedando con un pronóstico de vida reservado, sin embargo debido a esto y a problemas económicos y familiares la madre pide alta solicitada.

\section{DISCUSIÓN}

El caso presentado es interesante para cualquier médico ya que son eventos 
Tabla 3: Estudios laboratoriales solicitados por el servicio de gastroenterologia, con fecha del 09 de Noviembre del 2018.

\begin{tabular}{|c|c|c|c|c|c|c|c|c|}
\hline GB & $\mathrm{HGB}$ & PLAQ & HTO & TP & $\mathrm{TC}$ & TS & GOT & GTP \\
\hline $\begin{array}{l}17,300 \\
\mathrm{~mm} 3\end{array}$ & dl $5,3 \mathrm{gr} /$ & $\begin{array}{l}17,300 \\
\mathrm{~mm} 3\end{array}$ & $19,1 \%$ & $15 \mathrm{seg}$ & $8 \mathrm{~min}$ & $2 \min$ & $\begin{array}{l}80 \\
U / L\end{array}$ & $\begin{array}{l}140 \\
U / L\end{array}$ \\
\hline BT & $\mathrm{BI}$ & $B D$ & FA & PCR & & & & \\
\hline $\begin{array}{r}14.8 \\
\mathrm{mg} / \mathrm{dl}\end{array}$ & $\begin{array}{c}2.9 \\
\mathrm{mg} / \mathrm{dl}\end{array}$ & $\begin{array}{r}11.9 \\
\mathrm{mg} / \mathrm{dl}\end{array}$ & $\begin{array}{l}264 \\
U / L\end{array}$ & $(-)$ & & & & \\
\hline
\end{tabular}

GR/DL = gramos/decilitro, U/L = unidades/litro, MG/DL = miligramos decilitro, MM3 = milímetro cubico, SEG = segundos, MIN = minutos, VHA = virus de la Hepatitis A, VHB = virus de la Hepatitis B, VHC = virus de la Hepatitis C, CMV = citomegalovirus, $P C R=$ proteína $C$ reactiva

Tabla 4: Estudios serológicos solicitados, con fecha del 09 de Noviembre del 2018.

\begin{tabular}{|c|c|c|c|c|}
\hline VHA & VHB & $\mathrm{VHC}$ & CMG & TOXOPLASMOSIS \\
\hline$(-)$ & $(-)$ & $(-)$ & $(+)$ & $(-)$ \\
\hline \multicolumn{5}{|c|}{$\begin{array}{l}\text { VHA = virus de la Hepatitis } A, \text { VHB = virus de la Hepatitis } B, \text { VHC = virus de la Hepatitis C, } \\
\text { CMV = citomegalovirus }\end{array}$} \\
\hline
\end{tabular}

infrecuentes, por lo que al momento de encontrarnos con un paciente con una atresia de vías biliares podemos no atinar al diagnóstico de forma oportuna y con ello perjudicar al tratamiento. La "portoenterostomia de kasai" a corto plazo, es decir antes de los 2 meses de edad, es el tratamiento de elección, aún cuando esta no garantice una sobrevida a largo plazo, debido a las complicaciones que presentan. 6,7,8

Con nuestra paciente se tomó la decisión de realizar la conducta quirúrgica como lo indica la literatura, sin embargo por la edad fuera de limite (4 meses) que presentaba la paciente, se decidió en junta médica no optar por la portoenterostomia de Kasai, sino más bien por el trasplante hepático, una opción que era muy complicada para la familia por el aspecto económico.

En Japón se han observado sobrevidas hasta de 40 años en pacientes tratados con la operación de Kasai, lo importante en estos casos es la adaptación del hígado dañado a las exigencias metabólicas del cuerpo. ${ }^{11}$

En este caso la paciente dio positivo a citomegalovirus, por eso es recomendable realizar serología para citomegalovirus y demás virus durante el control prenatal a la mujer embarazada, además de realizar serología de TORCH a todo recién nacido, esto para prevenir las infecciones de transmisión vertical al neonato ya que hasta el momento no existen vacunas que puedan prevenirlas.

\section{CONCLUSIÓN}

La atresia de vías biliares es una patología infrecuente, pudiendo ser confundida con una ictericia fisiológica del recién nacido. $Y$ esto provoca que se pierda tiempo valioso para el diagnóstico y tratamiento oportuno. Es importante además enseñar a la mujer embarazada las medidas preventivas para citomegalovirus, como también realizar los controles serológicos correspondientes tanto a la madre como al recién nacido, todo esto para actuar de la manera más pronta ante un caso de atresia de vias biliares. 


\section{REFERENCIAS}

1. Crawford J, Chen L: Hígado y vias biliares. Robbins Stanley I, Cotran R, Kumar V, Collins T: Patología Estructural y Funcional. 8a Edición. Madrid España: ElSevier; 2011.p.833-890. Disponible en: https://www.elsevier.com/books/robbinsy-cotran-patologia-estructural-y-funcional/ kumar/978-84-9022-878-4

2. Herrero Santos J.I: Ictericias y enfermedades de las vias biliares. Farreras P, Rozman C: Medicina Interna. 17a edición. Barcelona - España: ElSevier.2012. p.250-264. Disponible en: https:// www.elsevier.com/books/farreras-rozmanmedicina-interna-enfermedades-del-aparatodigestivo-gastroenterologia-y-hepatologia/ unknown/978-84-9022-509-7

3. Silverio García C.E, Pérez Valencia D.C, Villamil Martinez R, Sosa Palacios O, Cobas Torres Y: Patrón clínico y epidemiológico de la atresia de vias biliares en Cuba. Revista Cubana de Pediatría. 2018. [citado el 28 de diciembre de 2019]; 90(4). Disponible en: http://www.revpediatria.sld.cu/index.php/ped/ article/view/709/225

4. Xu X, Rahbar A, Omarsdottir S, Teng J, Nemeth A, Fischler B, Soderberg-Naucler C: CD13 Autoantibodies are elevated in sera from mothers of infants with neonatal cholestasis of different causes. Journal of Pediatric Gastroenterology \& Nutrition.2017. [citado el 1 de septiembre del 2019]; 64(1).76-82.Disponible en: https://journals. Iww.com/jpgn/Fulltext/2017/01000/CD13 Autoantibodies_Are_Elevated_in_Sera_From.14. aspx

5. Herrine S, Navarro V, Rubín R: El hígado y el sistema de vias biliares. Rubín R, Strayer D: Patología. Fundamentos Clinicopatologicos en Medicina.6a Edición. Barcelona - España: Wolters Kluwer Lippincott Williams \& Wilkins. 2012. p.667-736.

6. Montaño Pérez C.M, Menéndez Auld N.G, SCJ Sainz Castro R: Atresia de vias biliares. Acta medica grupo ángeles. [citado el 28 de diciembre de 2019];
2016. 14(2). p114-116. Disponible en: https://www. medigraphic.com/pdfs/actmed/am-2016/am162k. pdf

7. Greenberger N, Paumgartner G. Enfermedades de la vesícula biliar y las vias biliares. Harrison, Fauci, Braunwald, Kasper, Hauser, Longo, Jameson, Loscalzo: Principios de Medicina Interna.18a edición. México:McGraw-Hill.2012.p.2615-2628. Disponible en: https://accessmedicina.mhmedical.com/ content.aspx?bookid=1717\&sectionid=114935525

8. Hackam D, Grikscheit T, Wang K, Newman K, Ford H: Cirugía Pediátrica. Schwartz S: Principios de Cirugía. 9a Edición. México: McGraw - Hill Inter americana.2011.p.1409-1455. Disponible en: https:// accessmedicina.mhmedical.com/content.aspx?boo kid $=1513 \&$ sectionid $=98632842$

9. Robalino Torres EA, Aldeán Riofrío JR, Cisne Argüello MC, Calvopiña Del Castillo J, Espinoza Arregui V. Hallazgos por imagen en pacientes con atresia de vias biliares en el Hospital de Especialidades Carlos Andrade Marín en el periodo de enero 2016 - marzo 2017. Cambios Rev. Méd. 2018. [Citado el 28 de diciembre de 2019]:17(1):8185. Disponible en: http://docs.bvsalud.org/ biblioref/2019/03/981162/articulo-15.pdf

10. Crehuet Gramatyka D, Navarro Rubio G., Manejo terapéutico de la atresia de vias biliares, Rev Pediatr Aten Primaria. 2016 [citado el 5 de septiembre del 2019]; 18:e141-e147. Disponible en: http:// scielo.isciii.es/scielo.php? script=sci_arttext\&pid $=$ S1139-76322016000300018

11. Ramírez Hernández I Jiménez Urueta $P S$, Sánchez Michaca VJ, Tomita Arcos VH, Castañeda Ortiz RA, Atresia de vias biliares: Seguimiento y comportamiento clínico de pacientes operados con técnica de Kasai. Acta pediátr Mex. 2010 [citado el 10 de septiembre del 2019]; 31(5):201-205. Disponible en: http://ojs.actapediatrica.org.mx/index.php/ APM/article/download/270/270 